\title{
Penentuan Harga Pokok Produksi Dengan Metode Full Costing Sebagai Dasar Penetapan Harga Jual Pada UKM Tahu An Anugrah
}

\author{
Sintia Anggreani dan I Gede Sudi Adnyana \\ Program Studi Akuntansi, Institut Bisnis dan Informatika Kesatuan \\ Bogor, Indonesia \\ E-Mail: maitrisintia@gmail.com
}

Full Costing and

Cost of Goods

Manufacture

Submitted:

JANUARI 2020

Accepted: APRIL 2020

\begin{abstract}
Cost of Goods Manufacture is an important component that must be calculated by the company in order to determine the selling price of the product. SMEs are often wrong in calculating the Cost of Goods Manufacture they do. One of the mistakes made by SMEs in calculating the Cost of Goods Manufacture is that the calculations carried out are very simple and do not specify all costs used in the production process to produce a product. This study aims to analyze (1) the calculation of the Cost of Goods Manufacture in SMEs Tahu AN Anugrah , (2) the determination of Cost of Goods Manufacture with the full costing method in SMEs Tahu AN Anugrah, and (3) the difference in calculation of Cost of Goods Manufacture according to SMEs AN Anugrah and according full costing method and its effect on selling prices. The data used in this study are primary data and secondary data. The primary data used is obtained from the results of interviews and recording of information needed directly in SMEs Tahu AN Anugrah. While the secondary data are is obtained from literature studies such as previous journals, related books, documentation and reading in accordance with the research title. Research results show, there are differences in the calculation results of the Cost of Goods Manufacture carried out by the SMEs and by the full costing method. The calculation of Cost of Goods Manufacture by SMEs Tahu AN Anugrah for White Tofu products is Rp 200 and Yellow Tofu Rp 201.12 while by the full costing method for White Tofu products is Rp 218.41 and Yellow Tofu Rp 228.44. So that, there are differences in the calculation results, namely for White Tofu $R p 18.41$ and Yellow Tofu $R p$ 27.32. Differences in calculation are due to the full costing method is more detailed by including all elements of production costs. This shows that the method provides a more accurate calculation to be able to set a better selling price.
\end{abstract}

Keywords: cost of goods manufacture, full costing, selling prices, SMEs

\section{PENDAHULUAN}

Di era globalisasi, kemajuan teknologi dan zaman yang semakin berkembang pesat seperti saat ini, perusahaan berlomba-lomba dan saling bersaing dalam memproduksi dan menghasilkan produk yang disukai dan produk yang berkualitas bagi masyarakat. Dalam hal ini, berbagai perusahaan yang bergerak di bidang manufaktur terus bersaing untuk menjadi yang terdepan. Tidak hanya perusahaan besar, Usaha Kecil Menengah (UKM) juga ikut bersaing dan berlomba untuk menghasilkan produk yang berkualitas dan disukai masyarakat dengan tujuan menghasilkan laba yang optimal yang dapat memberikan manfaat saat ini maupun manfaat jangka panjang bagi perusahaan. Dalam setiap produksinya, perusahaan dalam bidang manufaktur harus bisa meminimalisasi biaya yang digunakan agar harga jual yang dihasilkan dapat bersaing di pasaran. Oleh karena itu, perusahaan dituntut untuk dapat mengendalikan biaya produksinya seminimal mungkin, pengendalian biaya yang dilakukan dapat berupa pengendalian terhadap harga pokok produksi sebagai dasar harga jual untuk produk yang dihasilkan.

JIAKES

Jurnal Ilmiah Akuntansi Kesatuan Vol. 8 No. 1, 2020 pg. 9-16 IBI Kesatuan
ISSN 2337-7852 E-ISSN 2721 - 3048 
Full Costing and

Cost of Goods

Manufacture

$\underline{10}$
Harga pokok produksi merupakan bagian terpenting yang harus dihitung oleh perusahaan untuk dapat menetapkan harga jual. Terdapat beberapa metode dalam perhitungan harga pokok produksi menurut kaidah akuntansi biaya, diantaranya yaitu metode full costing dan variabel costing. Menurut Mulyadi $(2012,16)$ dalam perhitungan harga pokok produksi dengan metode full costing, semua biaya yang termasuk untuk memproduksi suatu produk dimasukkan kedalam perhitungan harga pokok produksi, biaya tersebut antara lain biaya bahan baku langsung, biaya tenaga kerja, dan biaya overhead pabrik baik tetap maupun variabel. Sedangkan menurut Mulyadi $(2012,18)$ perhitungan harga pokok produksi dengan metode variabel costing hanya memasukan biaya-biaya yang bersifat variabel kedalam perhitungan harga pokok produksi untuk suatu produk, diantaranya yaitu biaya bahan baku, biaya tenaga kerja dan biaya overhead pabrik variabel. Dalam perhitungan harga pokok produksi dengan metode full costing, biaya tetap merupakan biaya yang dimasukkan kedalam perhitungan harga pokok produksi karena biaya tetap merupakan biaya yang melekat kepada produk, baik produk jadi atau produk yang masih dalam proses dan biaya tetap tersebut baru dapat habis ketika produk sudah terjual. Maka dari itu perusahaan dapat menghitung harga pokok produksi nya dengan akurat dan dapat menghasilkan harga jual produk yang tepat dan dapat bersaing di pasaran.

UKM Tahu AN Anugrah merupakan usaha kecil yang bergerak di bidang manufaktur yang memproduksi tahu setiap hari. Pada penelitian yang dilakukan penulis, UKM Tahu AN. Anugrah dalam menghitung harga pokok produksi dan menentukan harga jualnya masih menggunakan metode yang sederhana yang diperoleh dari pengalaman dalam memproduksi tahu, sehingga seringkali perhitungan harga pokok produksinya tidak tepat. Ketidaktepatan dalam perhitungan harga pokok produksi ini diakibatkan oleh tidak rincinya biaya-biaya yang masuk ke dalam biaya produksi termasuk biaya overhead.

Tidak rincinya biaya-biaya untuk dialokasikan sebagai biaya produksi ke dalam suatu produk, termasuk biaya overhead, dapat mengakibatkan kesalahan dalam perhitungan harga pokok produksi yang berimplikasi pada kesalahan penetapan harga jual. Jika UKM Tahu AN Anugrah masih menggunakan metode tersebut di dalam perhitungan harga pokok produksinya, maka akan dihasilkan perhitungan harga pokok produksi yang tidak akurat, sehingga penetapan harga jual produk pun tidak tepat yang mengakibatkan profit menjadi tidak optimal.

UKM Tahu AN Anugrah merupakan UKM Tahu yang memproduksi tahu setiap hari untuk dipasarkan ke pelanggan. Walaupun UKM Tahu AN Anugrah memproduksi tahu setiap hari, tetapi perkembangan usahanya relatif lamban dan kurang berkembang. Hal ini salah satunya disebabkan oleh kesalahan dalam perhitungan harga pokok produksi berakibat penetapan harga jual yang tidak tepat. Berdasarkan latar belakang dan masalah yang telah diuraikan di atas, penulis memilih untuk menerapkan metode full costing dalam menentukan harga pokok produksi pada UKM Tahu AN Anugrah. Metode ini merupakan metode yang membebankan seluruh biaya produksi baik yang berperilaku tetap ataupun variabel ke dalam produk. Sehingga dapat diperoleh perhitungan harga pokok produksi yang lebih akurat dan penetapan harga jual pun menjadi tepat. Hal ini yang menjadi referensi bagi penulis untuk menggunakan metode full costing dalam penelitian ini.

\section{TINJAUAN PUSTAKA}

\section{Harga Pokok Produksi}

Harga pokok produksi menurut Bastian Bustami Nurlela dalam buku Akuntansi Biaya $(2010,49)$ yaitu kumpulan biaya produksi yang terdiri dari bahan baku langsung, tenaga kerja langsung dan biaya overhead pabrik ditambah persediaan produk dalam proses awal dan dikurang persediaan produk dalam proses akhir. Harga pokok produksi terikat pada periode waktu tertentu, dan akan sama dengan biaya produksi apabila tidak 
ada persediaan produk dalam proses awal dan akhir. Sedangkan menurut Mulyadi dalam buku Akuntansi Biaya $(2012,14)$ "harga pokok produksi adalah sejumlah biaya yang terjadi untuk mengolah bahan baku menjadi produk jadi yang siap untuk dijual". Berdasarkan pengertian diatas, harga pokok produksi yaitu total biaya yang dikeluarkan untuk mengolah bahan baku menjadi barang jadi.

\section{Unsur-Unsur Harga Pokok Produksi}

Unsur-unsur harga pokok produksi menurut Riwayadi dalam buku Akuntansi Biaya $(2016,44)$ dapat diklasifikasikan ke dalam tiga jenis, yaitu:

1. Biaya Bahan Baku

Biaya bahan baku dapat diklasifikasikan menjadi dua, yaitu biaya bahan baku langsung dan biaya bahan baku tidak langsung. Bahan baku langsung adalah bahan yang dapat secara mudah dan akurat ditelusuri ke barang jadi. Bahan baku yang menjadi komponen utama barang jadi merupakan bahan baku langsung karena bahan ini dapat secara mudah dan akurat ditelusuri sampai ke barang jadi, contohnya: kayu untuk membuat perabot, kain untuk membuat baju, dan kulit untuk membuat sepatu. Biaya bahan baku langsung adalah biaya bahan baku langsung yang dipakai, misalnya pembelian bahan baku langsung sebanyak 1.000 kg dengan harga Rp5.000 per kg. Jika bahan baku langsung yang dipakai sebanyak $800 \mathrm{~kg}$, biaya bahan baku langsung sebesar Rp1.000.000 (200 kg x Rp5.000) merupakan nilai persediaan bahan baku langsung akhir (bahan baku langsung yang belum terpakai). Selanjutnya, bahan baku tidak langsung adalah bahan baku yang tidak dapat secara mudah dan akurat ditelusuri ke produk. Penelusurannya memerlukan biaya yang mahal dan hasilnyapun belum tentu akurat. Contoh bahan baku tidak langsung adalah bahan penolong, seperti paku yang dipakai untuk pembuatan perabot serta benang untuk pembuatan baju dan sepatu.

2. Biaya Tenaga Kerja Langsung

Tenaga kerja langsung adalah tenaga kerja yang terlibat langsung dalam pembuatan barang jadi dan pembayaran upahnya berdasarkan unit yang dihasilkan atau berdasarkan jam kerja, misalnya upah Rp50.000 per unit atau Rp5.000 per jam. Tenaga kerja yang terlibat langsung dalam pembuatan barang jadi tetapi upahnya dibayar harian atau bulanan tidak dapat dikategorikan tenaga kerja langsung karena upahnya tidak dapat ditelusuri secara mudah dan akurat ke barang jadi. Jika upahnya dibayarkan secara harian, pekerja yang menghasilkan dua unit produk per hari akan menerima upah sama dengan pekerja yang menghasilkan lima unit produk per hari. Oleh karena itu, tenaga kerja langsung terdiri atas tenaga kerja yang secara langsung terlibat dalam pembuatan barang jadi tetapi upahnya dibayar secara harian atau bulanan, dan tenaga kerja yang tidak terlibat secara langsung dalam pembuatan barang jadi seperti mandor dan manajer pabrik dan karyawan administrasi pabrik.

3. Biaya Overhead Pabrik

Biaya overhead pabrik adalah semua biaya produksi selain biaya bahan baku langsung dan biaya tenaga kerja langsung. Biaya overhead pabrik merupakan biaya tidak langsung produk. Jika dikaitkan dengan konsep biaya tidak langsung, biaya overhead pabrik adalah semua biaya produksi yang tidak dapat secara mudah dan akurat ditelusuri ke produk, contohnya biaya penyusutan bangunan pabrik, beban asuransi pabrik, beban bahan bakar dan sebagainya.

\section{Metode Full Costing}

Menurut Mulyadi dalam buku Akuntansi Biaya (2012, 17), Full costing merupakan metode penentuan kos produksi yang memperhitungkan semua unsur biaya produksi ke dalam kos produksi, yang terdiri dari biaya bahan baku, tenaga kerja langsung, dan biaya overhead pabrik baik yang berlaku variabel maupun tetap.

Biaya bahan baku

Biaya tenaga kerja langsung

XXX

Biaya overhead pabrik tetap
Full Costing and Cost of Goods Manufacture

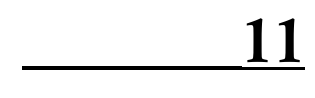


Full Costing and

Cost of Goods

Manufacture

$\underline{12}$
Biaya overhead pabrik variabel

Jumlah harga pokok produksi $\underline{\mathrm{xxx}}$

$\operatorname{xxx}$

\section{Penetapan harga biaya plus (Cost Plus Pricing)}

Dalam metode ini, harga jual per unit ditentukan dengan menghitung jumlah seluruh biaya per unit ditambah jumlah/persentase tertentu untuk menutupi laba yang dikehendaki pada unit tersebut (margin).

Harga jual $=$ Total Biaya $+($ Persentase Laba $x$ Biaya $)$

\section{METODOLOGI PENELITIAN}

Penelitian ini dilaksanakan di UKM Tahu AN Anugrah yang berlokasi di Kampung Cibucil RT 08 RW 03, Desa Sukamanah, Kecamatan Jonggol. Pemilihan lokasi penelitian dilakukan dengan sengaja (purposive) dengan pengamatan yang dilakukan penulis karena UKM Tahu ini adalah UKM Tahu yang cukup besar dan produknya digemari oleh masyarakat karena kualitasnya cukup baik. UKM ini termasuk usaha yang bergerak di bidang manufaktur yang memproduksi dan menjual tahu, sehingga cocok untuk dijadikan tempat penelitian mengenai harga pokok produksi sebagai dasar penetapan harga jual. Hal ini didukukung dengan kesediaan dari pemilik usaha untuk memberikan data yang dibutuhkan oleh penulis dalam penelitian ini.

Metode analisis yang digunakan dalam penelitian ini adalah analisis deskriptif yang bersifat kualitatif. Dengan metode ini, penulis berusaha menggambarkan secara jelas keadaan objek penelitian yang sebenarnya dengan mengumpulkan data yang tersedia dan relevan. Selanjutnya penulis menyusun, mempelajari, dan menganalisis lebih lanjut substansi mengenai harga pokok produksi metode full costing dan harga jual produk.

\section{HASIL DAN PEMBAHASAN}

UKM Tahu AN Anugrah merupakan usaha yang bergerak dibidang manufaktur yang melakukan produksi dan memasarkan Tahu setiap hari. Dalam satu hari, UKM Tahu AN Anugrah dapat memproduksi Tahu dengan menghabiskan bahan baku sebanyak delapan kwintal (800 kilogram) kacang kedelai yang dapat menghasilkan 22.400 buah Tahu, artinya dalam satu bulan ada 672.000 buah Tahu yang dihasilkan dari 240 kwintal (24.000 kilogram) kacang kedelai. Dalam satu bulan, UKM Tahu AN Anugrah hanya memproduksi Tahu Kuning sebanyak 30\% dari total seluruh Tahu yang dihasilkan, artinya 70\% Tahu yang dihasilkan dari delapan kwintal (800 kilogram) kacang kedelai digunakan untuk membuat Tahu Putih.

Tabel 1 Perbandingan HPP Menurut UKM Tahu AN Anugrah dan Menurut Metode Full Costing (Rp)

\begin{tabular}{lcccccc}
\hline & \multicolumn{2}{c}{ Metode UKM } & \multicolumn{2}{c}{ Metode Full Costing } & \multicolumn{2}{c}{ Selisih } \\
& $\begin{array}{c}\text { Tahu Putih } \\
(1)\end{array}$ & Tahu Kuning & Tahu Putih & Tahu Kuning & Tahu Puth & Tahu Kuning \\
$(2)$ & $(3)$ & $(4)$ & $(5)=(3)-(1)$ & $(4)-(2)$ \\
\hline \multirow{2}{*}{ Total HPP } & 94.080 .000 & 40.545 .000 & $102.730 .541,90$ & $46.052 .375,10$ & $8.650 .541,90$ & $5.507 .375,10$ \\
\multirow{2}{*}{ HPP Per Unit } & 200 & 201,12 & 218,41 & 228,44 & 18,41 & 27,32 \\
\hline
\end{tabular}

Sumber: Data Sekunder Diolah

Berdasarkan Tabel 1 dapat dilihat bahwa adanya selisih antara hasil perhitungan total harga pokok produksi maupun harga pokok produksi per unit yang dihitung oleh UKM Tahu AN Anugrah dan dengan metode full costing. Dimana untuk Tahu Putih pada total harga pokok produksi menghasilkan nilai selisih lebih rendah sebesar Rp8.650.541,90 dan Rp18,41 untuk harga pokok produksi setiap potong Tahu yang dihasilkan. Produk Tahu Kuning menghasilkan selisih lebih rendah sebesar sebesar Rp5.507.375,10 untuk total harga pokok produksi dan harga pokok produksi per potong Tahu nya menghasilkan selisih lebih rendah sebesar Rp27,32. 
Pada bulan April 2019, UKM Tahu AN Anugrah dapat memproduksi Tahu Putih sebanyak 470.400 potong dan Tahu Kuning sebanyak 201.600 potong, artinya selisih yang diperoleh untuk biaya produksi Tahu Putih pada bulan april adalah sebesar Rp 8.660.064 dan untuk Tahu Kuning sebesar Rp 5.507.712. Selisih yang dihasilkan dikarenakan adanya biaya overhead pabrik yang tidak dimasukkan ke dalam perhitungan harga pokok produksi oleh UKM Tahu AN Anugrah, tapi di dalam metode full costing semua biaya secara lebih rinci diperhitungan kedalam perhitungan harga pokok produksi.

Tabel 2 Perbandingan Harga Jual Produk Menurut UKM Tahu AN Anugrah dan Menurut Metode Full Costing (Rp)

\begin{tabular}{ccccccc}
\hline & \multicolumn{2}{c}{ Metode UKM } & \multicolumn{2}{c}{ Metode Full Costing } & \multicolumn{2}{c}{ Selisih } \\
& $\begin{array}{c}\text { Tahu Puth } \\
(1)\end{array}$ & $\begin{array}{c}\text { Tahu Kuning } \\
(2)\end{array}$ & $\begin{array}{c}\text { Tahu Puth } \\
(3)\end{array}$ & $\begin{array}{c}\text { Tahu Kuning } \\
(4)\end{array}$ & $\begin{array}{c}\text { Tahu Puth } \\
(5)=(3)-(1)\end{array}$ & $\begin{array}{c}\text { Tahu Kuning } \\
(6)=(4)-(2)\end{array}$ \\
\hline $\begin{array}{c}\text { Harga Jual } \\
\text { Per Unit }\end{array}$ & 280 & 281,57 & 305,77 & 319,82 & 25,77 & 38,25 \\
\hline
\end{tabular}

Sumber: Data Sekunder Diolah

Tabel 2 menunjukkan bahwa terdapat selisih harga jual yang dihitung oleh UKM Tahu AN Anugrah dan yang dihitung dengan menggunakan metode full costing. Selisih perhitungan harga jual untuk Tahu Putih sebesar Rp 25,77 dan untuk Tahu Kuning sebesar Rp 38,25. Selisih tersebut disebabkan karena adanya perbedaan perhitungan harga pokok produksi antara UKM Tahu AN Anugrah dan dengan perhitungan menggunakan metode full costing karena pada metode full costing biaya overhead pabrik baik tetap maupun variabel diperhitungkan dan dimasukkan ke dalam perhitungan harga pokok produksi, seperti: biaya kayu bakar, gas, listrik, air, solar, dan transportasi. Dengan adanya perbedaan perhitungan harga pokok produksi yang dihitung dengan metode yang berbeda, harga jual yang dihasilkan dengan metode UKM Tahu AN Anugrah lebih rendah dibandingkan dengan harga jual menurut metode full costing.

\section{PENUTUP}

Berdasarkan hasil analisis dan pembahasan, penulis dapat menyimpulkan bahwa:

1. UKM Tahu AN Anugrah melakukan perhitungan harga pokok produksi Tahu Putih dan Tahu Kuning dengan metode yang masih sederhana sejak berdirinya. Perhitungan harga pokok produksi tersebut hanya memasukkan biaya-biaya yang terlihat saja, seperti biaya bahan baku dan biaya tenaga kerja langsung tanpa menghitung biaya overhead. Biaya overhead tersebut baik yang berperilaku tetap seperti biaya penyusutan kendaran maupun berperilaku variabel seperti biaya kayu bakar, solar, gas, listrik, air dan transportasi belum mereka perhitungkan. Hasil perhitungan harga pokok produksi yang dilakukan oleh UKM Tahu AN Anugrah untuk produk Tahu Putih dan Tahu Kuning per potong nya adalah sebagai berikut:

Tahu Putih: $\quad$ Rp. 200

Tahu Kuning: $\quad$ Rp. 201,12

2. Penentuan harga pokok produksi dengan metode full costing dilakukan dengan menghitung semua komponen biaya yang termasuk ke dalam biaya produksi. Biaya-biaya tersebut meliputi biaya bahan baku, biaya tenaga kerja langsung, dan biaya overhead. Biaya overhead tersebut baik yang berperilaku tetap seperti biaya penyusutan kendaran maupun berperilaku variabel seperti biaya kayu bakar, solar, gas, listrik, air dan transportasi. Hasil perhitungan harga pokok produksi yang dilakukan dengan metode full costing untuk produk Tahu Putih dan Tahu Kuning per potong nya adalah sebagai berikut:

Tahu Putih: $\quad$ Rp. 218,41

Tahu Kuning: $\quad$ Rp. 228,44

3. Perhitungan harga pokok produksi dengan metode yang dilakukan UKM Tahu AN Anugrah dibandingkan dengan menggunakan metode full costing memberikan hasil
Full Costing and Cost of Goods Manufacture 
Full Costing and

Cost of Goods

Manufacture

\section{$\underline{14}$}

yang berbeda. Hasil perhitungan harga pokok produksi dengan metode full costing menghasilkan nilai yang lebih besar daripada hasil perhitungan dengan metode UKM. Selisih harga pokok produksi antara metode full costing dan metode UKM untuk produk Tahu Putih adalah Rp 18,41 per potongnya. Dalam satu bulan, UKM Tahu AN Anugrah dapat menghasilkan 470.400 potong Tahu Putih, artinya selisih harga pokok produksi selama bulan April 2019 adalah sebesar Rp 8.660.064. Sedangkan untuk tahu kuning, selisihnya sebesar $R p$ 27,32 per potongnya dan dalam satu bulan UKM Tahu AN Anugrah memproduksi tahu kuning sebanyak 201.600 potong, artinya selisih harga pokok produksi selama bulan april 2019 sebesar Rp5.507.712.

Dari perhitungan tersebut diketahui bahwa selama bulan April 2019 selisih perhitungan harga pokok produksi keseluruhan dari produk Tahu Putih dan Tahu Kuning adalah sebesar Rp 14.167.776.

Pengaruh perbedaan hasil perhitungan di atas terhadap harga jual dapat dijelaskan sebagai berikut. Harga jual yang dihasilkan dengan metode UKM Tahu AN Anugrah adalah sebagai berikut :

Tahu Putih : Rp 280

Tahu Kuning $\quad:$ Rp 281,57

Harga jual yang dihasilkan dengan metode cost plus pricing dalam full costing adalah sebagai berikut :

Tahu Putih $\quad:$ Rp 305,77

Tahu Kuning : : Rp 319,82

Harga jual yang dihasilkan dengan metode cost plus pricing dalam full costing lebih besar dibandingkan harga jual yang dihitung dengan menggunakan metode UKM Tahu AN Anugrah, selisih yang dihasilkan untuk produk tahu putih adalah sebesar Rp 25,77 dan untuk produk tahu kuning sebesar Rp 38,25 per potongnya.

Untuk itu, direkomendasikan agar UKM Tahu AN Anugrah menggunakan metode full costing dalam perhitungan harga pokok produksinya karena metode full costing memasukkan semua unsur biaya produksi. Dengan menggunakan metode full costing, hasil perhitungan menjadi lebih tepat dan akurat yang dapat memberikan keuntungan untuk perkembangan usaha yang dimiliki oleh UKM Tahu AN Anugrah pada saat ini maupun pada masa yang akan datang.

Selain itu, UKM Tahu AN Anugrah hendaknya menyusun laporan biaya produksi dengan lebih baik dan memperhitungkan biaya-biaya yang dikeluarkan dengan lebih rinci agar biaya yang dianggap tidak ada menjadi terlihat lebih jelas sehingga perhitungan harga pokok produksi menjadi lebih mudah dan akurat

\section{DAFTAR PUSTAKA}

Astarani, M. dan Uliana, A. 2013. Analisis Penentuan Biaya Produksi Listrik Dengan Metode Full Costing Pada PT.PLN (Persero) Wilayah Kalimantan Barat Area Pontianak. Jurnal Audit dan Akuntansi. Universitas Tanjungpura, Pontianak.

Bastian, Bustami dan Nurlela. 2010. Akuntansi Biaya. Graha Ilmu, Yogyakarta.

Batubara, Helmina. 2013. Penentuan Harga Pokok Produksi Berdasarkan Metode Full Costing pada Pembuatan Etalase Kaca dan Alumunium di UD Istana Alumunium Manado. Skripsi. Universitas Sam Ratulangi, Manado.

Crysti, Yulia. 2018. Analisis Penentuan Harga Jual Bakso Dengan Metode Cost Plus Pricing Pada Warung Bakso Rudal Tonjong. Tugas Akhir. Universitas Gunadarma, Depok.

Eka, Andri. 2014. Penerapan Full Costing Method Melalui Perhitungan HPP Sebagai Dasar Penentuan Harga Jual Pada UKM Tahu Pak Dariyo. Skripsi. Universitas Dian Nuswantoro, Semarang.

Eprilianta, Silvania. 2011. Analisis Perhitungan Harga Pokok Produksi Tahu dengan metode Full Costing pada Industri Kecil (Studi Kasus CV Laksa Mandiri). Skripsi. Institut Pertanian Bogor, Bogor. 
Fadillah, A., Sujana, S. and Sukartaatmadja, I., 2019. Kajian Minat Studi Lanjut Siswa-Siswi SMA dan SMK Kota Bogor Ke Perguruan Tinggi. JAS-PT (Jurnal Analisis Sistem Pendidikan Tinggi Indonesia), 3(1), pp.53-62.

Firmansyah, Iman., 2014. Akuntansi Biaya Itu Gampang. Cetakan Kesatu, Dunia Cerdas, Jakarta.

Garisson, Ray, H, Eric, W.N, dan Petter, C.B. 2014. Akuntansi Manajerial. Salemba Empat, Jakarta.

Jasinski, Dominik, Maredith.J, dan Kirwan.K. 2015. A comprehensive review of full cost accounting methods and their applicability to the automotive industry. University Of Warwick, United Kingdom.

Komara Bintang dan Sudarma Ade. 2016. Analisis Penentuan Harga Pokok Produksi dengan Metode Full Costing Sebagai Dasar Penetapan Harga Jual pada CV. Salwa Meubel. Skripsi. Universitas Muhammadiyah, Sukabumi.

Krismiaji dan Anni, Aryani. 2011. Akuntansi Manajemen. Unit Penerbit dan Percetakan Sekolah Tinggi Ilmu Manajemen YKPN, Yogyakarta.

Muktiadji, N., Hidayat, L. and Melinda, M., 2007. Analisis Modal Kerja dalam Pengendalian Likuiditas dan Profitabilitas Studi Kasus pada PT. Indocement Tunggal Prakarsa, Tbk. Jurnal Ilmiah Ranggagading (JIR), 7(1), pp.37-44.

Mulyadi., 2010. Akuntansi Biaya. Unit penerbitan dan percetakan Sekolah Tinggi Ilmu Manajemen YKPN, Yogyakarta.

Mulyadi., 2012. Akuntansi Biaya. Edisi Kelima, Unit penerbit Sekolah Tinggi Ilmu Manajemen YKPN, Yogyakarta.

Mulyadi., 2014. Akuntansi Biaya. Unit penerbitan dan percetakan Sekolah Tinggi Ilmu Manajemen YKPN, Yogyakarta.

Nirwanto, Rasditya. 2011. Analisis Perhitungan Harga Pokok Produksi Kopi Pada Tingkat Petani Kopi Di Kecamatan Kembang Kabupaten Bondwoso. Skripsi. Universitas Jember, Jember.

Nurfitasari, E. dan Sunrowiyati, S. 2014. Analisis Perhitungan Beban Pokok Produksi Dengan Metode Variabel Costing Sebagai Alat Perencanaan Laba Pada PR. Alaina Tulungagung. Riset Mahasiswa Ekonomi. STIE Kusuma Negara Blitar, Blitar.

Oritama, N.B.C. 2018. Analisis Perhitungan Harga Pokok Produksi Untuk Menentukan Harga Jual Produk. Skripsi. STIE Kesatuan Bogor, Bogor.

Pamungkas, B. and Afrianti, V., 2006. Evaluasi Akuntansi Pertanggungjawaban sebagai Alat Bantu Manajemen dalam Pengendalian Biaya: Studi Kasus pada PT. Cahaya Buana Intitama. Jurnal Ilmiah Ranggagading (JIR), 6(1), pp.7-13.

Parawouw, Silvia. 2013. Analisis Perbandingan Metode Penentuan Harga Pokok Produksi Pada PT. Bangun Wenang Beverages Co. Skripsi. Universitas Sam Ratulangi Manado, Manado.

Paranita. 2017. Analisis Penetapan Harga Pokok Produksi Dalam Kaitannya Penentuan Harga Jual Produk (studi kasus pada PT. Bangun Multilindo Angkasa). Skripsi. STIE Kesatuan Bogor, Bogor.

Renzetti, S dan Kushner, J. 2004. Full cost accounting for water supply and sewage treatment: concepts and case application. Brock University, Kanada.

Riwayadi., 2016. Akuntansi Biaya. Edisi 2, Salemba Empat, Jakarta.

Rosaly, A.F. 2016. Perhitungan Cost Of Production Dengan Metode Biaya Penuh Pada Usaha Kecil dan Menengah (Studi Kasus UKM Tahu Eco). Skripsi. Universitas Dian Nuswantoro, Semarang.

Salman R.K dan Farid, M. 2016. Akuntansi Manajemen. Indeks Jakarta, Jakarta.

Samryn., 2015. Akuntansi Manajemen. Edisi Ketiga, Kencana Pernada Media Group, Jakarta.

Sari, Pujiartina. 2017. Analisis Penerapan Metode Akumulasi Biaya Sebagai Alat Untuk Menentukan Harga Pokok Produksi (Studi Kasus Pada PT.X). 1. STIE Kesatuan Bogor, Bogor.
Full Costing and Cost of Goods Manufacture 
Full Costing and Cost of Goods

Manufacture
Siregar, Baldric, dkk. 2016. Akuntansi Biaya. Salemba Empat, Jakarta.

Supriyono., 2013. Akuntansi Biaya dan Penentuan Harga Pokok. Edisi Kedua, BPFE, Yogyakarta.

Tjiptono., 2008. Akuntansi Biaya. PT Citra Media, Bandung.

Widilestariningtyas, Et al. 2012. Edisi Kesatu, Graha Ilmu, Yogyakarta.

Wahyuningsih, Sri., 2013. Metode Penelitian Studi Kasus. UTM PRESS, Madura.

Witjaksono, Armanto., 2013. Akuntansi Biaya. Edisi Revisi, Graha Ilmu, Yogyakarta.

Yusiawati, Vera. 2017. Analisis Penentuan Harga Pokok Produksi Dengan Metode Activity Based Costing Sebagai Penentuan Harga Jual (Studi Kasus Pada Setia Jaya). Skripsi. STIE Kesatuan Bogor, Bogor.

Zuhdi, S., Daud, A., Hanif, R., Nguyen, P.T. and Shankar, K., 2019. Role of Social Media Marketing in the Successful Implementation of Business Management. International Journal of Recent Technology and Engineering, 8 (2S11). 